\title{
Foreign Trade and Social Inequity in the Andean Community of Nations-CAN
}

\author{
Emma Beatriz Castro Urbano \\ Autónoma de Occidente University, Cali, Colombia
}

\begin{abstract}
This paper was made using a descriptive analysis of some indicators from the data basis of Economic Commission for Latin America (CEPAL), CEPAL and answers the question: Have there been enough foreign trade dynamics during the last years (1999-2006) in order to reduce social inequality gaps? The results here shown correspond to the first stage of a research that relates poverty to countries' economic productivity. The article presents foreign trade, economic growth, and social inequality overview in the countries of the Andean Community of Nations during the years 1999-2006. In considering this period, the last international crisis is overlooked, but it takes in account the importance of the Millennium Development Goals set by the UNDP. The analysis of the basic indicators reflects that the dynamics of economic integration and foreign trade do not translate into better social equality and poverty reduction. This paper shows an economic and social contrast obtained from the results by countries of the Andean Community of Nations (CAN) during the years 1999-2006, comprised by Colombia, Peru, Ecuador, Bolivia, and Venezuela, though the last country is not currently part of CAN. These indicators are exports, imports, relative commercial balance, gross domestic product, gross domestic product per capita, unemployment, GINI index, population, urban development index, and poverty. The paper presents a succinct conceptual framework where the relationship between foreign trade and social inequality is established, from which the description and analysis of the proposed indicators is formulated, permitting the establishing of an apparent practical connection between economic behavior and social results from the CAN countries.
\end{abstract}

Keywords: economic integration, quality of life, social equality, poverty

\section{The Relationship Between Economic Growth and Social Inequality}

In the literature about income growth and distribution, a concept has been widely disseminated and questioned - the existence of a positive relationship in a long-term, according to Kuznets approach (Kuznets, 1955). He argues that the relationship that can exist between growth (measured through per capita income) and inequality can be understood within a general framework of an evolution of an economy, without necessarily having to be understood as sequential stages. When countries start to growth they present a very equitable income distribution which degenerates, getting worse until it reaches the maximum point, from which point a better equity is obtained.

In this context, the tendency is that both the wealthiest and poorest countries have less inequity than the nations with medium income.

Emma Beatriz Castro Urbano, MBA, Professor, Group of Research GIED, Autónoma de Occidente University. Correspondence concerning this article should be addressed to Emma Beatriz Castro Urbano, Calle 25\# 115-85 Km. 2 Vía Cali-Jamundí, Cali, Colombia. E-mail: ebcastro@uao.edu.co. 
In terms of poverty, for the eradication of poverty, Bhagwati (1996) set forth two ways to reach this objective: direct channel, which imply governmental actions to satisfy the corresponding needs (like offers and subsidies), and an indirect channel, which corresponds to plans and programs intended for the income increase of the population.

The World Bank points out that even though globalization is a powerful force contributing to positive economic growth and reduction of poverty levels, it is also true that in these marketing and commercial integration processes nations assume diverse risks, and for this reason, it is important to establish policies that minimize those risks, and on the contrary to generate environments that maximize opportunities for the poor population in general. In other words, there are actions of economic policy that are necessary to take, according to the condition of each economy (Collier \& Dollar, 2002).

\section{Foreign Trade and Social Inequality in the Andean Community of Nations}

Foreign trade and social inequality are closely related through an inverse association, the larger the commerce the lower social inequality index exists. According to this approach, in this stage of research, this paper try to see through foreign trade analysis, the unemployment rate, gross domestic product per capita, the GINI index, and human development, among others, that close socioeconomic relationship.

Table 1 summarizes the total foreign trade (exports and imports) of this group of countries. During the analysis period 1999-2006, the CAN increased its foreign trade by $168.9 \%$, where Colombia and Venezuela are the countries of the most participation, with $70.4 \%$ in 1999 and 66.8\% in 2006. It's important to note that all of the countries present a growth above $100.0 \%$, Ecuador being the highest with $232.6 \%$, followed by Peru with $206.4 \%$.

Table 1

Foreign Trade and Trade Relative Balance-TRB

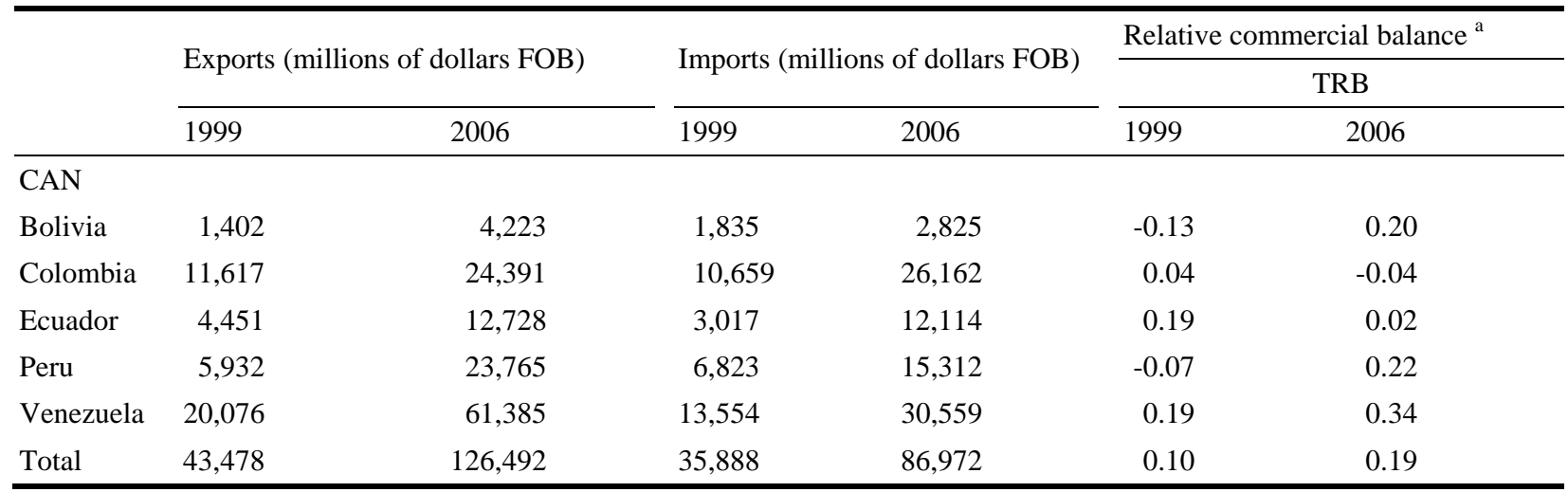

Notes. ${ }^{\mathrm{a}}$ This indicator allows know the tendency (exports and imports) in that particular activity involve in the total commerce foreign of a economy. The BCR have a range that around between 1 and -1 with the following levels of levels measurement: $-1 \leqslant$ RTB $\leqslant-0.33$, the economy is net importer; $-0.33<$ RTB $<0.33$, the economy is in equilibrium; $0.33<$ RTB $<1$, the economy is net exporter. Source: Authors' calculations based on statistics from CEPAL 2009 (Retrieved from http://www. cepal.org, 2011).

In turn, this commercial flow reflects that in general these nations have made important efforts to develop a diversified foreign trade in goods, services and markets. With regard to this, it is important to note that the degree of economic opening (measured in millions of dollars), according to data from Statistics Annual from the CEPAL (2009), was increased within the analyzed period. Between 2001 and 2006, Bolivia went from 45.2 
to 74.5, Colombia from 37.1 to 39.8, Ecuador from 57.9 to 67.0, Peru from 33.3 to 48.4, and Venezuela from 42.1 to 57.1. In general, a considerable increase has been observed in these processes, apart from Colombia which has maintained relatively constant. In terms of the commercial relative balance indicator, this hints that the foreign trade result of these economies brings balance, that is to say, there is as abundance of exports as of imports which are benefitting foreign trade dynamics. These indicators seem reinforced through the exchange terms, which have favored foreign trade dynamics (see Figure 1).

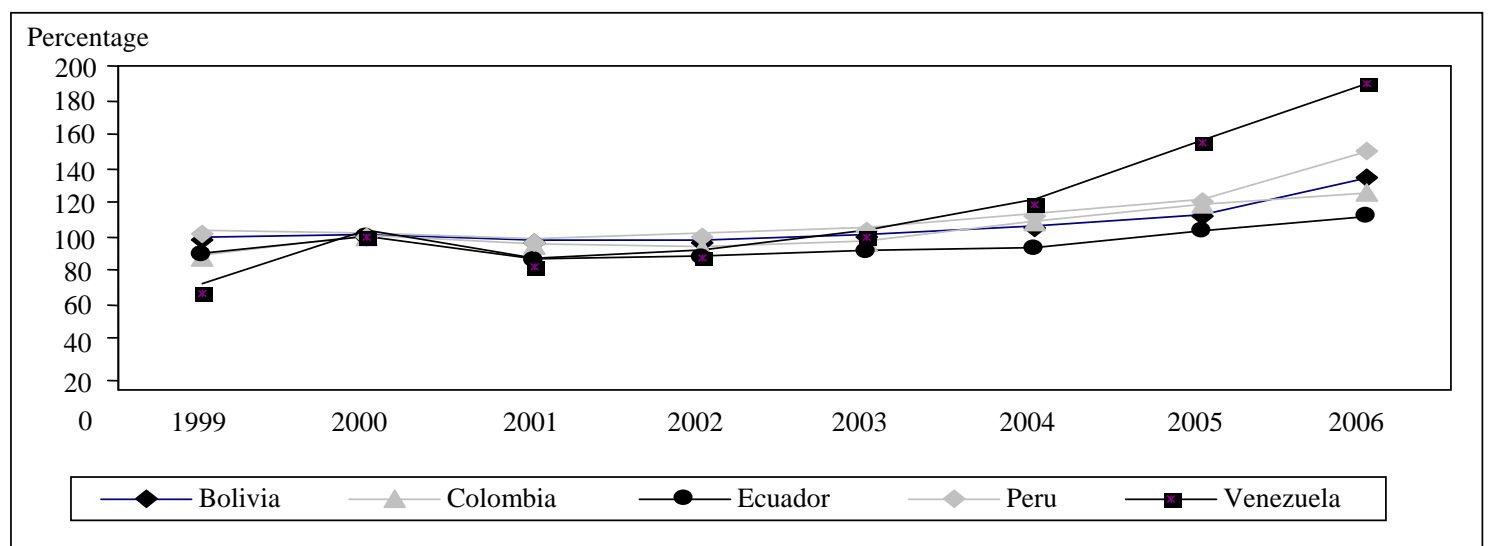

Figure 1. Evolution of the exchange of goods terms. FOB/FOB (Index $2000=100$ ). Source: Authors' calculations based on statistics from CEPAL 2009 (Retrieved from http://www. cepal.org, 2011).

Table 2 shows the trade of each country within the CAN countries. It is observed that they represent a low participation in comparison to the rest of the world, and an apparent explanation for this situation could be that these economies still are very dependent on foreign trade with only one country. This is the case for Colombia and Ecuador, whose biggest market for both countries is United States.

Table 2

Intraregional Trade of Goods 2006 (Millions of Dollars FOB)

\begin{tabular}{lccc}
\hline & Total block commerce (1) & Total world commerce (2) & Relation (1)/(2) \\
\hline Colombia & 8,142 & 50,553 & 16.1 \\
Bolivia & 936 & 7,048 & 13.3 \\
Ecuador & 4,412 & 24,841 & 17.8 \\
Peru & 4,142 & 39,076 & 10.6 \\
Venezuela & 4,053 & 91,944 & 4.4 \\
Total CAN & 21,685 & 213,462 & 12.9 \\
\hline
\end{tabular}

Note. Source: Authors' calculations based on statistics from CEPAL 2009 (Retrieved from http://www. cepal.org, 2011).

What can be said regarding GDP? Figure 2 shows the rate of growth of the real GDP from each of the CAN countries and reflects, in general, an increase from 1999, though moderate, placing the median long term growth at 2.84. Venezuela is an atypical case with a sharp decrease between 2002 and 2003, and an increase in 2004.

Trying to associate economic growth with foreign trade in the CAN group of countries, Figure 3 reflects that the lines behave similarly, coinciding greatly in 2002, when both indicators show the strongest decline of the study period. These results give indications about the positive relationship that the two variables present in the CAN economies. 


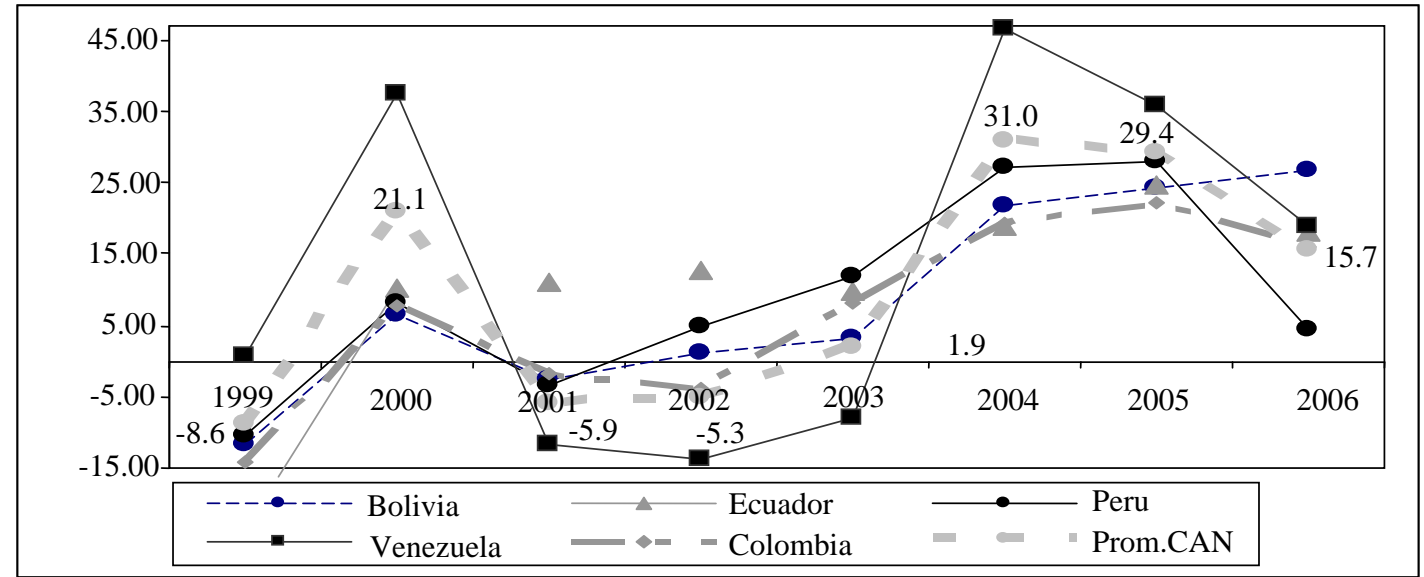

Figure 2. Rate of growth of PIB real CAN (Dollars of 2000). Source: Authors' calculations based on statistics from CEPAL 2009 (Retrieved from http://www. cepal.org, 2011).

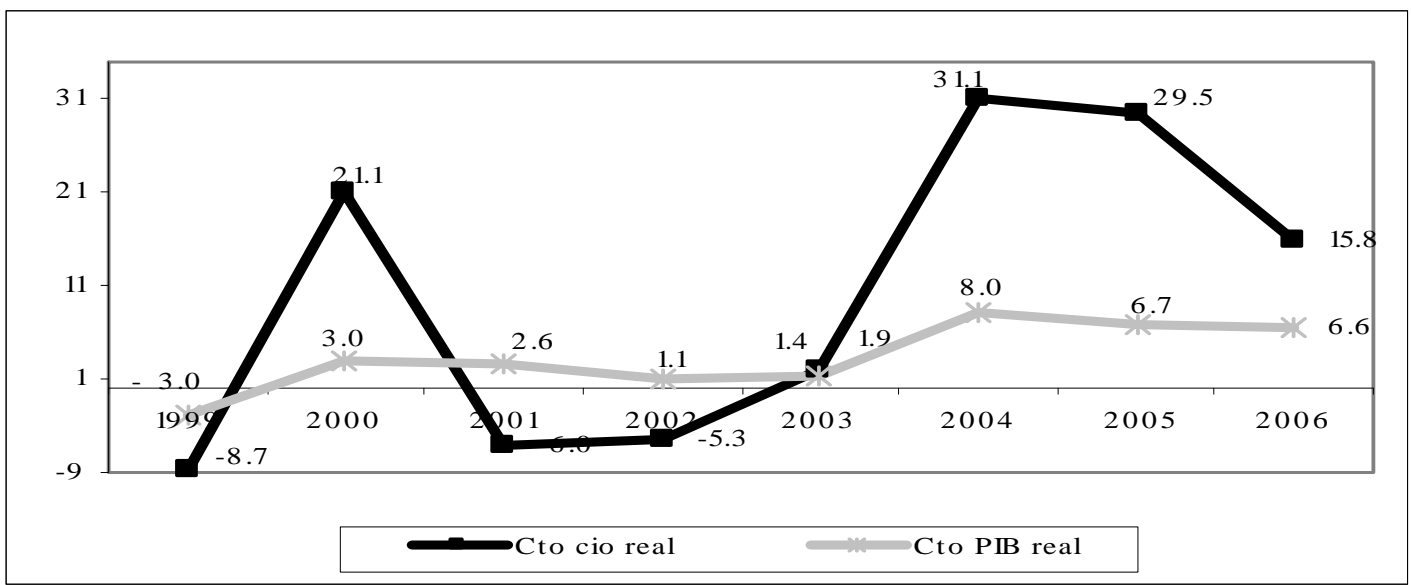

Figure 3. Rates of growth of the GDP and of foreign trade-CAN. Source: Authors' calculations based on statistics from CEPAL 2009 (Retrieved from http://www. cepal.org, 2011).

What can be said of the social panorama, and specifically, in respect to social inequality? Unemployment, a socio-economical hybrid indicator that generates a direct impact of the productivity, as well as from the satisfaction of its needs of the population, reflects that the countries maintain very high unemployment rates for the proportion of the population of its economies and its level of development. The CAN unemployment rate average was $12.5 \%$ in 1999 and 9.4\% in 2006 (see Figure 4).

A high unemployment rate, linked to inequitable income redistribution processes is transferred to low results of the GDP per capita, very far from reaching of the median level of developed countries (25,000 dollars U\$ PPA) the Table 3 records the GDP per capita from the CAN countries and shows a quite precarious situation for these countries, despite showing a better dynamic in its trade in the last years, apart from 2006 which was the year previous to the worsening of the crisis.

In short, the foreign trade dynamics have not been enough to close the gap of inequality among the population. In the income distribution, the Gini index of these countries finds itself devoid of an equitable tendency. The data from Table 4 and the information recorded in Table 5 complement each other very well. This last one validates the assertion that Bolivia has always had the highest Gini index in the CAN for all its population, surprising Colombia which went from having a high level in 2005 to a very low Gini. 


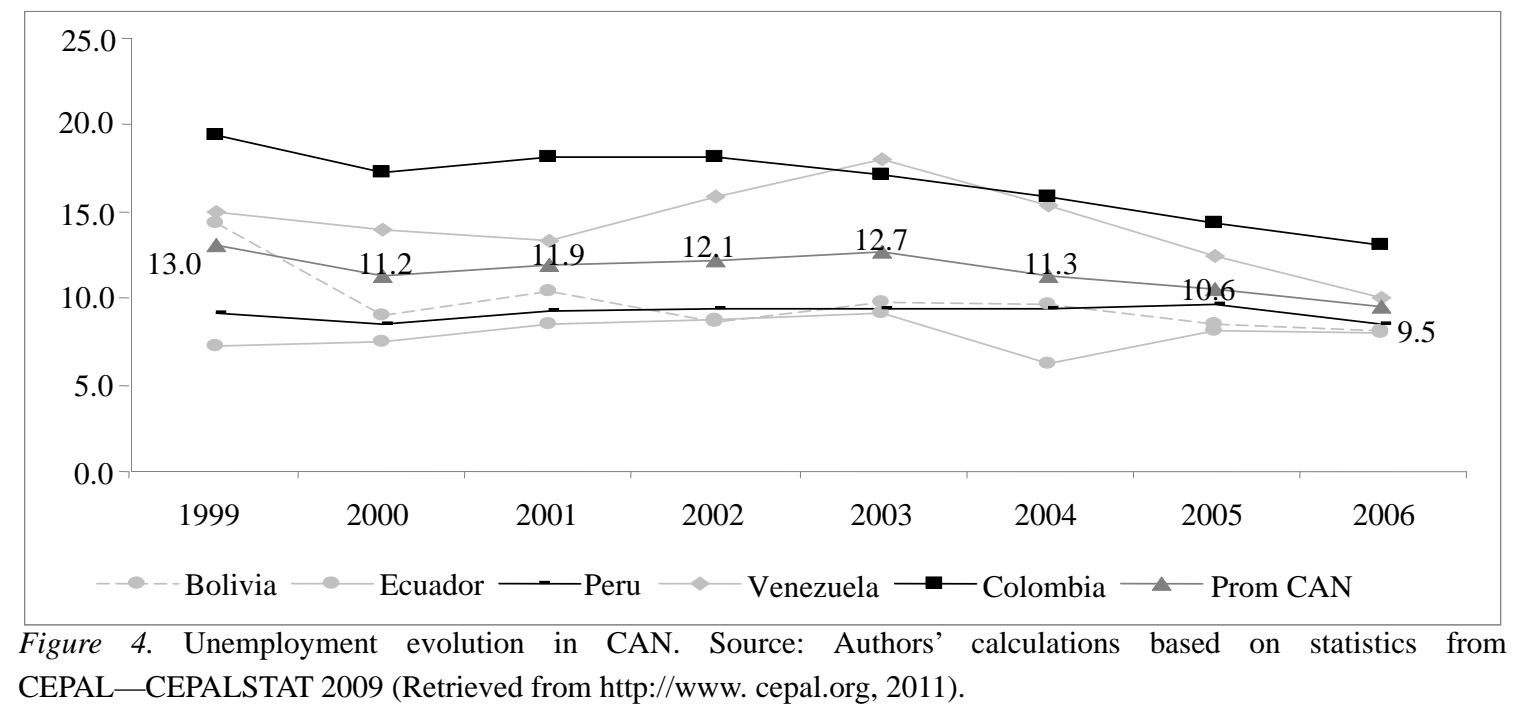

Table 3

Gross Domestic Product per Habitant

\begin{tabular}{lcc}
\hline & 1999 & 2006 \\
\hline CAN & & \\
Bolivia & 1,006 & 1,096 \\
Colombia & 2,337 & 2,789 \\
Ecuador & 1,277 & 1,632 \\
Peru & 2,024 & 2,504 \\
Venezuela & 4,720 & 5,370 \\
CAN average $^{*}$ & 2,273 & 2,678 \\
\hline
\end{tabular}

Notes. * Average unemployment rate of trade block. Source: Authors' calculations based on statistics from CEPAL-CEPALSTAT 2009 (Retrieved from http://www. cepal.org, 2011).

Table 4

Gini Index

\begin{tabular}{lll}
\hline & Last years of 1990s & First years of century 21 \\
\hline CAN & & \\
Bolivia & 0.586 & 0.565 \\
Colombia & 0.572 & 0.584 \\
Ecuador & $0.526^{*}$ & 0.504 \\
Perú & 0.525 & 0.576 \\
Venezuela & 0.500 & 0.490 \\
\hline
\end{tabular}

Notes. $^{*}$ Corresponds to the urban area. Source: Authors' calculations based on statistics from CEPAL-CEPALSTAT 2009 (Retrieved from http://www. cepal.org, 2011).

A contrasting indicator, which signals what governments can be doing to improve living conditions for the population, is the Human Development Index. This improves from 0.772 in 2001 to 0.753 in 2007 internationally, according to the PNUD. However, even though Latin America appears in the poverty and human development charts with higher indicators to the total median reached in its group (middle incomes), today, Latin America is considered as a region with great social inequality (Perry, Arias, Lopez, Maloney, \& Serven, 2006; Ferreira \& Walton, 2004). 
Table 5

Stratification of Countries by Distribution of Revenue Gini Index

\begin{tabular}{|c|c|c|c|}
\hline Inequity level & $1998 / 1999$ & $2000 / 2002$ & $2003 / 2005$ \\
\hline \begin{tabular}{|l|} 
Very High \\
$0.580-1$ \\
\end{tabular} & Bolivia 0.586 & Bolivia 0.614 & \begin{tabular}{|l} 
Bolivia (2002) 0.614 \\
Colombia 0.584 \\
\end{tabular} \\
\hline $\begin{array}{l}\text { High } \\
0.520-0.579\end{array}$ & \begin{tabular}{|l|} 
Colombia 0.572 \\
Peru 0.545 \\
Ecuador 0.521 \\
\end{tabular} & $\begin{array}{l}\text { Colombia } 0.569 \\
\text { Peru } 0.525\end{array}$ & \\
\hline Medium level 0.470-0.519 & Venezuela 0.498 & Ecuador $^{*} 0.513$ Venezuela 0.500 & \begin{tabular}{|l|} 
Ecuador ${ }^{*} 0.513$ \\
Peru 0.505 \\
Venezuela 0.490
\end{tabular} \\
\hline
\end{tabular}

Notes. ${ }^{*}$ Urban area. Source: elaborated with data of Social Panorama of Latin América 2006 Naciones Unidas ECLAC.

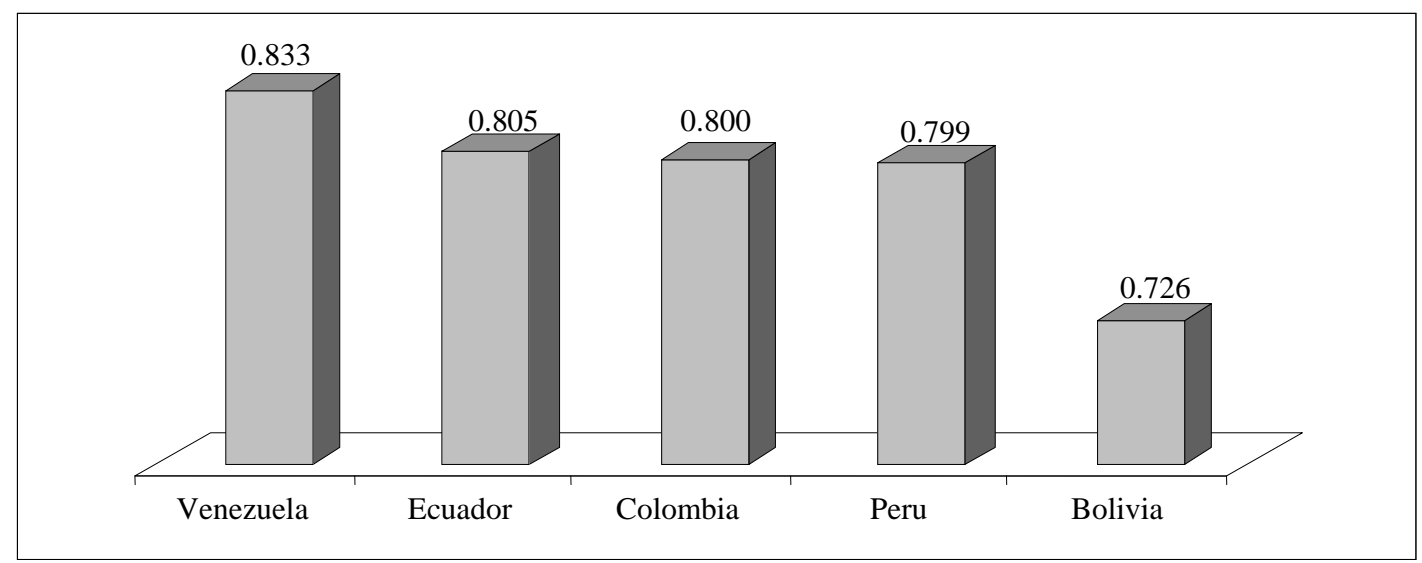

Figure 5. Human development index 2006. Source: Human Development Report 2009, United Nations, PNUD.

Below are shown the poverty results. According to Figure 5, even though the CAN countries' populations are mainly urban, Venezuela is the only country that has a considerably high percentage, unlike Bolivia and Ecuador which are the most rural countries. Though theoretically, from the point of view of economic growth, it is hoped that as the economies are more urban they have fewer poverty indicators, this is not exactly what is reflected for the CAN countries. In particular, supporting the Urban and Regional Economic Development thesis, according to which as cities grow they are more behave to social problems unless there are coherent public policies of planning, Colombia, the second most urban country in this group, has high poverty and urban homeless in relation to the context set out and, in general, to the rest of the countries in the CAN group (see Tables 6 and 7).

Table 6

Urban Population 2005 (Thousands of People)

\begin{tabular}{lccc}
\hline & National (1) & Urban (2) & Relation \% (1)/(2) \\
\hline CAN & & & 64.2 \\
Bolivia & 9,427 & 6,055 & 76.6 \\
Colombia & 44,907 & 34,409 & 62.8 \\
Ecuador & 13,211 & 8,299 & 72.7 \\
Peru & 27,254 & 19,804 & 92.8 \\
Venezuela & 26,556 & 24,636 & 72.3 \\
Total & 94,799 & 68,567 & \\
\hline
\end{tabular}

Note. Source: Authors' calculations based on statistics from CEPAL—CEPALSTAT 2009 (Retrieved from http://www. cepal.org, 2011). 
Table 7

Poverty and Extreme Urban Poverty (Total Population Percentage)

\begin{tabular}{|c|c|c|c|c|}
\hline & \multicolumn{2}{|c|}{ Urban poverty } & \multicolumn{2}{|c|}{ Urban poverty extreme } \\
\hline & Finals of decade 1990s & Middle decade of 2010 & Finals of decade 1990s & Middle decade of 2010 \\
\hline \multicolumn{5}{|l|}{ CAN } \\
\hline Bolivia & 48.7 & 53.8 & 19.8 & 20.2 \\
\hline Colombia & 43.1 & 45.4 & 21.9 & 18.2 \\
\hline Ecuador & 63.5 & 39.9 & 31.3 & 12.8 \\
\hline Peru & 36.1 & 31.2 & 9.3 & 4.9 \\
\hline Venezuela & $49.4^{*}$ & $30.2^{*}$ & $21.7^{* *}$ & $9.9^{* *}$ \\
\hline
\end{tabular}

\section{Conclusion}

The foreign trade reflects, in general, that the nations referenced in this papers, have made important efforts to develop a diversified commerce of goods and markets. In terms of the commercial relative balance indicator this hints that the foreign trade result of these economies brings balance, that is to say, there is as abundance of exports as of imports which are benefitting foreign trade dynamics

The trade of each country within the CAN countries been observed that they represent a low participation in comparison to the rest of the world; an apparent explanation for this situation could be that these economies still are very dependent on foreign trade with only one country. This is the case for Colombia and Ecuador, whose biggest market for both countries is United States.

The results of the apparent association between trade growth and the reduction of social inequality in the Andean countries show an unsatisfactory result, although if there is a positive relationship between economic growth and development of foreign trade

Theoretically, the foreign trade with the social inequality is closely related through an inverse association, in other words, if the commerce is low then there would exist a high social inequality. According to this approach, in this stage of research, this paper try to see the relationship between foreign trade and the unemployment rate, the gross domestic product per capita, the Gini index and human development index.

Finally, as a synthesis, economic growth and the dynamic of foreign trade are important for the CAN. But, this dynamic has not necessarily decreased the social inequality and the income gaps in its countries. Therefore, it can be said that a greater commercial integration is not enough to reach better conditions in terms of social equality.

It is important to note that this analysis is a preliminary diagnosis about the relationships that can exist between foreign trade and social inequality, in the case of the countries from CAN.

\section{References}

Balassa, B. (1986). Intraindustry specialization. European Economic Review, 30(1), 27-42.

Bhagwati, J. (1996). Political economy and international economics. In A. Douglas (Ed.), Poverty and public policy (pp. 539-555). Irwin, MIT.

CEPAL. (2009). Statistical yearbook for Latinamerica and the Caribbean, Statistics and Economic Projections Division, 2010, Santiago de Chile.

CEPAL stat. (2009). Data bases and statistical publications. Economic commission for Latin-American and Caribbean. Retrieved from http://www.eclac.org 
Collier, P., \& Dollar, D. (2002). Globalization, growth and poverty: Building and inclusive world (Chap. 1-2. pp. 23-82). A copublications of the World Bank and Oxford University Press.

Community Andean, (2006). Main indicators of the South America Community of Nations 1994-2005. Retrieved from http://www.comunidadandina.org/estadísticas

Ferreira, F., \& Walton, M. (2004). Inequality in Latin America: Breaking with History? World Bank. Series Development for All 1. Document 34866.

Kuznets, S. (1955). Economic growth and income inequality. American Economic Review, 45, 1-28.

Perry, G., Arias, O., Lopez, H., Maloney, W., \& Serven, L. (2006). Poverty reduction and growth: Virtuos and vicious circles. The World Bank. Chap. 2.

United Nations. (2006). Social panorama of Latin América, preliminary version. Social Development Division \& Statics and Economy Projections Division of ECLAC.

United Nations. (2009). Development programme UNDP. Human Development Report.

World Bank. (2009). The World Bank annual report, No. 50175, Washington, D.C.. 